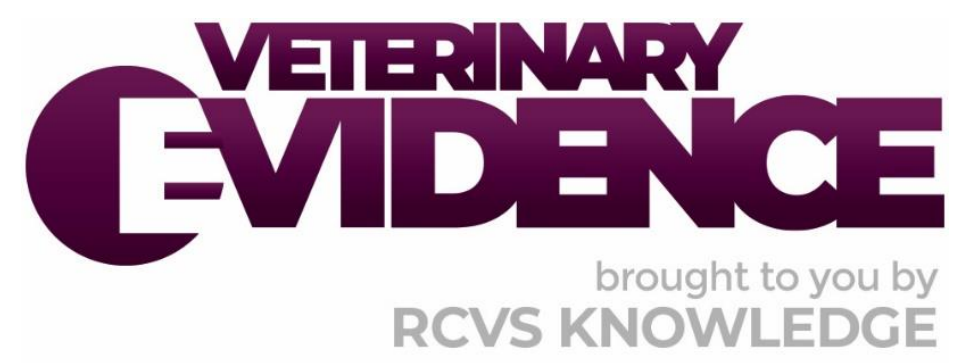

\title{
Does Pet Remedy Reduce Stress in Dogs?
}

\author{
A Knowledge Summary by \\ Louise Buckley PhD RVN ${ }^{1^{*}}$ \\ ${ }^{1}$ Royal (Dick) School of Veterinary Studies, University of Edinburgh
${ }^{*}$ Corresponding Author (louise.buckley@bristol.ac.uk)
}

ISSN: 2396-9776

Published: 16 Sep 2019

in: Vol 4, Issue 3

DOI: https://doi.org/10.18849/ve.v4i3.219

Reviewed by: Sienna Taylor (MSc, BSc (Hons), FdSc; FHEA) and

Debbie Emmerson (BSc (Hons), MSc CABC)

Next Review Date: Jun 12th 2021 
KNOWLEDGE SUMMARY

\section{PICO question}

In stressed dogs, does using a Pet Remedy diffuser, compared to not using one, result in lowered stress levels?

\section{Clinical bottom line}

Three studies were reviewed, two that investigated Pet Remedy and one that investigated Valerian (an active ingredient in Pet Remedy) on aspects of canine behaviour associated with stress. The highest quality study was a randomised controlled trial that found that Pet Remedy had no significant effect on particularly stresssusceptible dogs exposed to an acute stressor. The weakest quality study was a randomised controlled trial that found a significant positive effect, but had high levels of industry involvement, weak and incomplete scientific reporting and methodology, and was not peer-reviewed prior to publication. Thus, the findings are unreliable. The final study, which was a quasi-experimental, fixed treatment order, controlled trial, found a positive effect of environmentally applied Valerian (on its own) on behaviour in shelter dogs. However, experimental design limited interpretation of the findings in relation to canine stress reduction, and external validity in relation to applicability to Pet Remedy use is weak.

Where used as an adjunct, Pet Remedy is unlikely to do any direct animal welfare harm and may have a positive effect, based on studies that have unreliable findings and/or low external validity. However, unless further high quality research demonstrates a positive effect of Pet Remedy, veterinary professionals should be cautious about recommending it as an alternative to options with a stronger evidentiary basis, or as a delay to seeking more extensive professional support where needed. There is a need for further research to examine the efficacy of Pet Remedy on behavioural and physiological indices of canine stress reduction across a range of common stressful scenarios to further support veterinary professional decision making.

\section{Clinical Scenario}

During veterinary clinics, you find that clients are asking you about a herbal diffuser, Pet Remedy, that they have seen marketed in pet shops and online, as a method to reduce stress levels in dogs and make them calmer. They notice that the product has been endorsed by a human psychiatrist as efficacious in dogs but wonder what you, the veterinary professional, think about this product. You pause, think, and realise that you do not know anything at all about this product so decide to undertake a review of the published scientific literature in order to be able to provide the client with evidence-based advice. You also note that the manufacturer reports having studies to support the product's use so decide to contact them direct for further details.

\section{The evidence}

Three studies were included in this Knowledge Summary, of which one found no efficacy of Pet Remedy in a stressed dog sample (Taylor and Madden, 2016), one found that it was efficacious at improving behaviour/reducing excitability in a sample of dogs that might be stressed (Unex Designs Ltd., 2014), and one found a significant positive effect of Valerian alone (not as part of the Pet Remedy product) that might reflect lowered stress levels (Binks et al., 2018). Two of the studies (Taylor and Madden, 2016; Unex Designs Ltd. 2014) used the product Pet Remedy in their clinical trial, and were supported financially by the producers of Pet Remedy (Unex Designs Ltd., Torquay, Devon, UK). The Binks et al. (2018) was tentatively included due to Valerian being a key component of Pet Remedy, shelter dogs being a population of dogs identified as experiencing stress (Hermiston et al., 2018) and the mode of administration (environmental application, but not diffuser). However, 
when interpreting the efficacy of Pet Remedy based on these findings this should be borne in mind. One study (Taylor and Madden, 2016) purposively selected dogs subjectively assessed as stressed by the owners for inclusion in the study, and one study provides insufficient detail to assess this aspect (Unex Designs Ltd., 2014). All of the studies focused on behavioural parameters, and there are currently no studies that examined the effects of Pet Remedy (or its constituent parts applied environmentally/topically) on physiological indicators of stress.

Two studies (Taylor and Madden, 2016; Unex Designs Ltd., 2014) used a randomised controlled trial design and the other (Binks et al., 2018) used a fixed treatment order, quasi-experimental, controlled trial design. Two of the studies were published in peer-reviewed scientific journals (Binks et al., 2018; Taylor and Madden, 2016). The other (Unex Designs Ltd. 2014) was obtained by public request from the producer of Pet Remedy and has not been through the peer review process but is supplied direct to veterinary professionals asking for evidence as to the efficacy of the product. This study contained insufficient experimental detail to fully appraise key aspects of the study design (including the method of delivering Pet Remedy or what the placebo was, essential sample population details or behavioural protocols used), and the findings for most outcome measures were not reported.

\section{Summary of the evidence}

\section{Taylor and Madden (2016)}

\begin{tabular}{|c|c|}
\hline Population: & $\begin{array}{l}\text { Adult (1-11-years-old, mean: } 4.6 \text { years) pet dogs of any breed, sex } \\
\text { or neuter status that had previously exhibited signs of stress, plus } \\
\text { anxiety in new situations (as reported by the owner in a pre- } \\
\text { selection interview). } \\
\text { Dogs that were aggressive to strangers or too anxious to handle } \\
\text { safely were excluded from the trial. }\end{array}$ \\
\hline Sample size: & 28 dogs \\
\hline Intervention details: & $\begin{array}{l}\text { This study was a cross over design, with each dog used as its own } \\
\text { control. Dogs were randomly allocated to their order of treatment } \\
\text { (how is not specified). } \\
\text { The two interventions were: } \\
\text { 1. Placebo control } \\
\text { 2. Pet Remedy } \\
\text { The Pet Remedy product was a commercially available preparation } \\
\text { that includes a } 5.37 \% \text { essential oil blend (Valerian, Vetiver, Basil and } \\
\text { Sage) in a volatile base, delivered via a diffuser. } \\
\text { The placebo used the same diffuser type containing only the volatile } \\
\text { base. } \\
\text { Dogs were randomly allocated to the order in which they } \\
\text { experienced the two treatments to control for order effects (1. } \\
\text { Placebo first, followed by Pet Remedy: } n=15 ; 2 \text {. Pet Remedy first, } \\
\text { followed by Placebo: } n=13 \text { ), with approximately } 7 \text { days between } \\
\text { the dog receiving each treatment. }\end{array}$ \\
\hline
\end{tabular}




\begin{tabular}{|c|c|}
\hline & $\begin{array}{l}\text { A power calculation was used to determine appropriate sample size. } \\
\text { The statistical analysis was a multivariate regression analysis, with } \\
\text { treatment, individual dog and order of treatment as fixed effects. } \\
\text { Experimental set up: } \\
\text { The test pen was a room novel to the dog (at the start of the study), } \\
\text { that measured } 3 \times 3 \text { m, and contained a bed, bowl, and diffuser. A } \\
\text { camera allowed remote recording of the dog. The room had } \\
\text { washable walls, floor and internal furniture and a built-in fan, with } \\
\text { all being cleaned between subjects/tests and a two day period left } \\
\text { between testing any two dogs to allow any diffuser residual smells } \\
\text { to dissipate. } \\
\text { Testing procedure: } \\
\text { The diffuser was turned on } 30 \text { minutes before the test subject (dog) } \\
\text { entered. The dog was placed into the room alone for } 30 \text { minutes } \\
\text { (the details of this process are missing). A camera filmed the dog's } \\
\text { behavior over the thirty minutes. The dog was then removed. Thus, } \\
\text { the length of each treatment was } 30 \text { minutes, with approximately } 7 \\
\text { days between treatments. } \\
\text { Data analysis: } \\
\text { The video footage was renamed by a naïve assistant so that the } \\
\text { researcher was blind to the treatment the dog was receiving at the } \\
\text { time. The researcher recorded the behaviours according to a pre- } \\
\text { prepared ethogram of behaviours (see outcome measures). } \\
\text { The University of Exeter's ethical review group approved the study. }\end{array}$ \\
\hline Study design: & Randomised controlled trial \\
\hline Outcome studied: &  \\
\hline
\end{tabular}




\begin{tabular}{|c|c|c|}
\hline & & $\begin{array}{l}\text { Frequency with which each of the following behaviours was } \\
\text { performed: } \\
\text { - } \text { Barking } \\
\text { - Howling } \\
\text { - Nose licking } \\
\text { - } \quad \text { Paw lifting } \\
\text { - } \quad \text { Sighing } \\
\text { - } \quad \text { Whining } \\
\text { - Yawning } \\
\text { - Urination/defecation } \\
\text { - Panting }\end{array}$ \\
\hline $\begin{array}{l}\text { Main findings: } \\
\text { (relevant to PICO question): }\end{array}$ & 1. & $\begin{array}{l}\text { Duration of time behaviours performed: } \\
\text { - There was no effect of treatment on the duration of } \\
\text { time with which each of the } 14 \text { behaviours recorded } \\
\text { were performed. Although order of treatment exposure } \\
\text { was built into the statistical model, the authors do not } \\
\text { report this finding in the results. } \\
\text { Frequency with which behaviours performed: } \\
\text { - There was no effect of treatment on the frequency } \\
\text { with which the nine behaviours recorded were } \\
\text { performed. Dogs exposed to Pet Remedy tended to } \\
\text { sigh less }(P=0.052) \text {. }\end{array}$ \\
\hline Limitations: & & $\begin{array}{l}\text { The study was industry funded (by Unex Designs Ltd.) } \\
\text { The inclusion criteria were based on subjective assessment } \\
\text { by the owners, with no attempt to standardise level of } \\
\text { 'stress' between dogs (or to control for it statistically). } \\
\text { The treatment groups were not evenly allocated to control } \\
\text { for order effects. } \\
\text { The authors do not report whether the dogs were currently } \\
\text { taking any medications or other supplements that might } \\
\text { have an anti-stress/anxiolytic effect. } \\
\text { Insufficient detail is provided with regards to how the dog } \\
\text { was handled in the lead up to entering the room e.g. was } \\
\text { the owner present immediately prior to testing } \\
\text { commencing, was this standardised between dogs, etc.? } \\
\text { Some of the behaviours measured are not clear measures of } \\
\text { stress. }\end{array}$ \\
\hline
\end{tabular}

\begin{tabular}{|c|c|}
\hline \multicolumn{2}{|l|}{ Binks et al (2018) } \\
\hline Population: & $\begin{array}{l}\text { Healthy adult (18 months-9-years-old, mean age: } 4 \text { years and } 4 \\
\text { months) neutered dogs in a UK rescue centre. The sample } \\
\text { population was mainly male }(=13) \text {, mainly medium sized }(=13) \text { and } \\
\text { mainly bull breed or bull breed crosses }(n=10) \text {. }\end{array}$ \\
\hline Sample size: & 15 dogs \\
\hline
\end{tabular}




\begin{tabular}{|c|c|}
\hline Intervention details: & 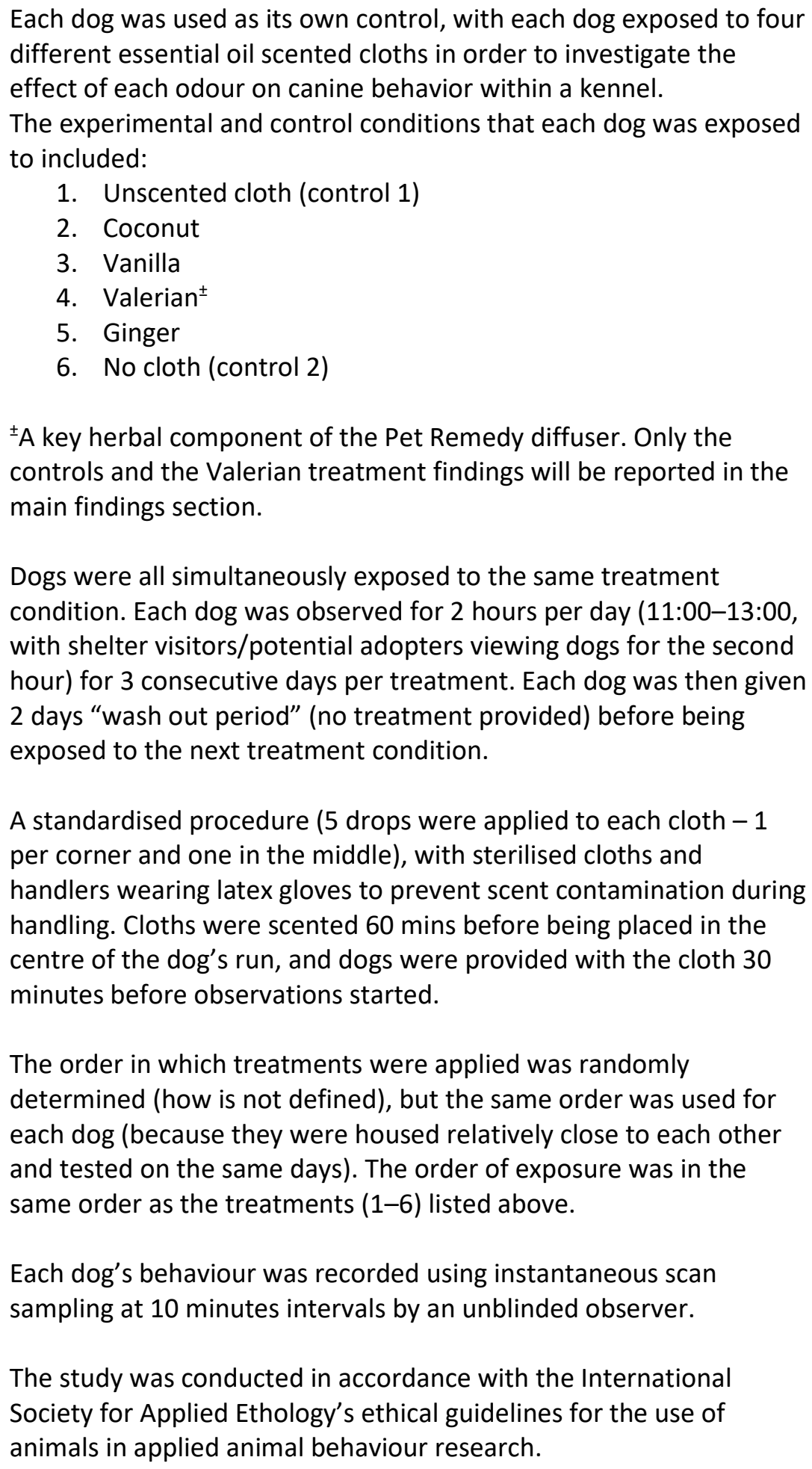 \\
\hline Study design: & Fixed order of treatments, controlled trial \\
\hline Outcome studied: & $\begin{array}{l}\text { The frequency of observation points in which the dog was showing } \\
\text { the following behaviours/location: } \\
\text { 1. Standing } \\
\text { 2. Sitting } \\
\text { 3. Moving } \\
\text { 4. Resting } \\
\text { 5. Sleeping }\end{array}$ \\
\hline
\end{tabular}




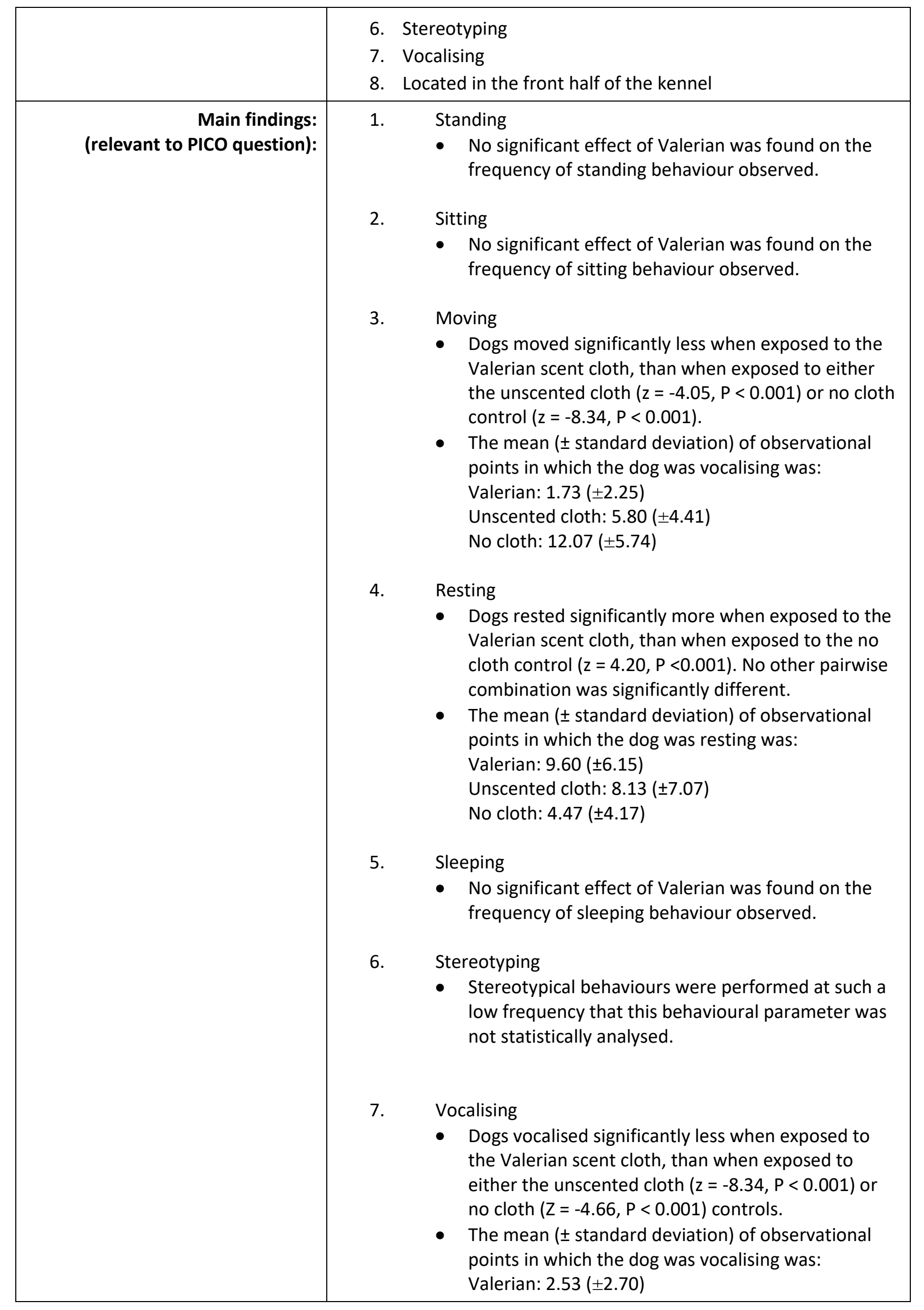




\begin{tabular}{|c|c|}
\hline & $\begin{array}{l}\text { Unscented cloth: } 8.67( \pm 6.42) \\
\text { No cloth: } 13.87( \pm 8.84) \\
\text { Located in the front half of the kennel } \\
\text { - No significant effect of Valerian was found on the } \\
\text { frequency of times the dog was observed to be in } \\
\text { the front half of the kennel. }\end{array}$ \\
\hline Limitations: & $\begin{array}{l}\text { - The observer was not blinded to treatment. } \\
\text { - As the study aim was not specifically to look at the effect of } \\
\text { Valerian on stress, the pre-existing stress levels of the dogs } \\
\text { was not assessed. } \\
\text { - The dogs considered (by rescue centre employees) to be } \\
\text { most susceptible to stress were excluded. } \\
\text { - All dogs received the same treatment at the same time and } \\
\text { in the same order so the study is particularly sensitive to } \\
\text { order effects and stochastic events that might influence dog } \\
\text { behaviour during a particular treatment condition. } \\
\text { - None of the behaviours measured in the ethogram are } \\
\text { indicators unique to stress. } \\
\text { - All of the behaviours that were significantly affected by } \\
\text { Valerian could be used as measures of arousal more } \\
\text { generally without reference to the emotional valence } \\
\text { (positive or negative) per se. } \\
\text { Limited range of behaviours observed. }\end{array}$ \\
\hline
\end{tabular}

\begin{tabular}{|c|c|}
\hline \multicolumn{2}{|l|}{ Unex Designs Ltd. (2014) } \\
\hline Population: & $\begin{array}{l}\text { Dogs (various breeds, ages and both sexes) with behavioural issues } \\
\text { (for example anxiety, nervousness or aggression). The authors do } \\
\text { not provide further demographic detail (e.g. age range). }\end{array}$ \\
\hline Sample size: & 66 dogs ( 33 dogs per treatment group) \\
\hline Intervention details: & $\begin{array}{l}\text { Two treatment groups, with each dog used as its own control: } \\
\text { 1. Behavioural therapy + placebo } \\
\text { 2. Behavioural therapy + Pet Remedy } \\
\text { On arrival dogs were given a behavioural assessment, the behaviour } \\
\text { issue identified and a behavioural programme that was partly } \\
\text { tailored to the individual dog was devised. } \\
\text { Dogs were allocated to the treatment group by the order in which } \\
\text { they presented at the clinic (alternated between groups). The } \\
\text { handler and trainer was blinded to which treatment group dogs } \\
\text { were allocated to. } \\
\text { Each dog was assessed at four time points: } \\
\text { 1. January (baseline measurement) }\end{array}$ \\
\hline
\end{tabular}




\begin{tabular}{|c|c|}
\hline & $\begin{array}{l}\text { 2. February } \\
\text { 3. March } \\
\text { 4. April } \\
\text { With data collected at time points 2-4 being compared to the } \\
\text { baseline measurement for each dog. } \\
\text { Each dog, and handler, came to the Animal Behaviour Centre on } \\
\text { several occasions each month to work with the trainer on a } \\
\text { combination of set exercises, plus exercises specific to the individual } \\
\text { dog. The owner also undertook training at home. It is not stated } \\
\text { whether the number of centre visits, trainer(s) or at home training } \\
\text { sessions were standardised between dogs. The set exercises are not } \\
\text { fully defined, with only examples (hand feeding, door manners) of } \\
\text { the type of exercises provided. } \\
\text { It is not clear when or how the dog was exposed to the intervention } \\
\text { (Placebo or Pet Remedy, dependent upon the group the dog was in), } \\
\text { but it appears to have been within the training centre environment. } \\
\text { It is not clear exactly when and how the dogs were scored } \\
\text { (excitement/behavior) at each of the four time points. }\end{array}$ \\
\hline Study design: & Randomised controlled trial \\
\hline Outcome studied: & $\begin{array}{l}\text { Subjective measures were used: } \\
\text { 1. Behaviour score - ordinal scale ranging from } 0 \\
\text { (poor/unacceptable) to } 5 \text { (normal/good behaviour), with } \\
\text { half-points allowed. } \\
\text { 2. Excitement level - } 0 \text { (not excited) to } 5 \text { (very excited), with } \\
\text { half-points allowed. } \\
\text { For both measures, the data was handled as follows: } \\
\text { - The difference between the score/level awarded in January } \\
\text { (baseline) and each subsequent experimental month } \\
\text { (individually) was calculated for each dog. } \\
\text { - This 'differences' data for each experimental month was } \\
\text { compared statistically inter-treatment groups. } \\
\text { Other outcome measures: } \\
\text { 1. Licking of paws - yes/no } \\
\text { 2. Licking of bedding - yes/no } \\
\text { 3. Suckling - yes/no } \\
\text { 4. Paw over lead - yes/no } \\
\text { 5. Jumping up - yes/no } \\
\text { 6. Turning in circles - yes/no }\end{array}$ \\
\hline $\begin{array}{l}\text { Main findings: } \\
\text { (relevant to PICO question): }\end{array}$ & $\begin{array}{l}\text { Subjective measures: } \\
\text { 1. Behaviour score } \\
\text { - The median (range) behaviour score for the placebo group } \\
\text { was: }\end{array}$ \\
\hline
\end{tabular}




\begin{tabular}{|c|}
\hline 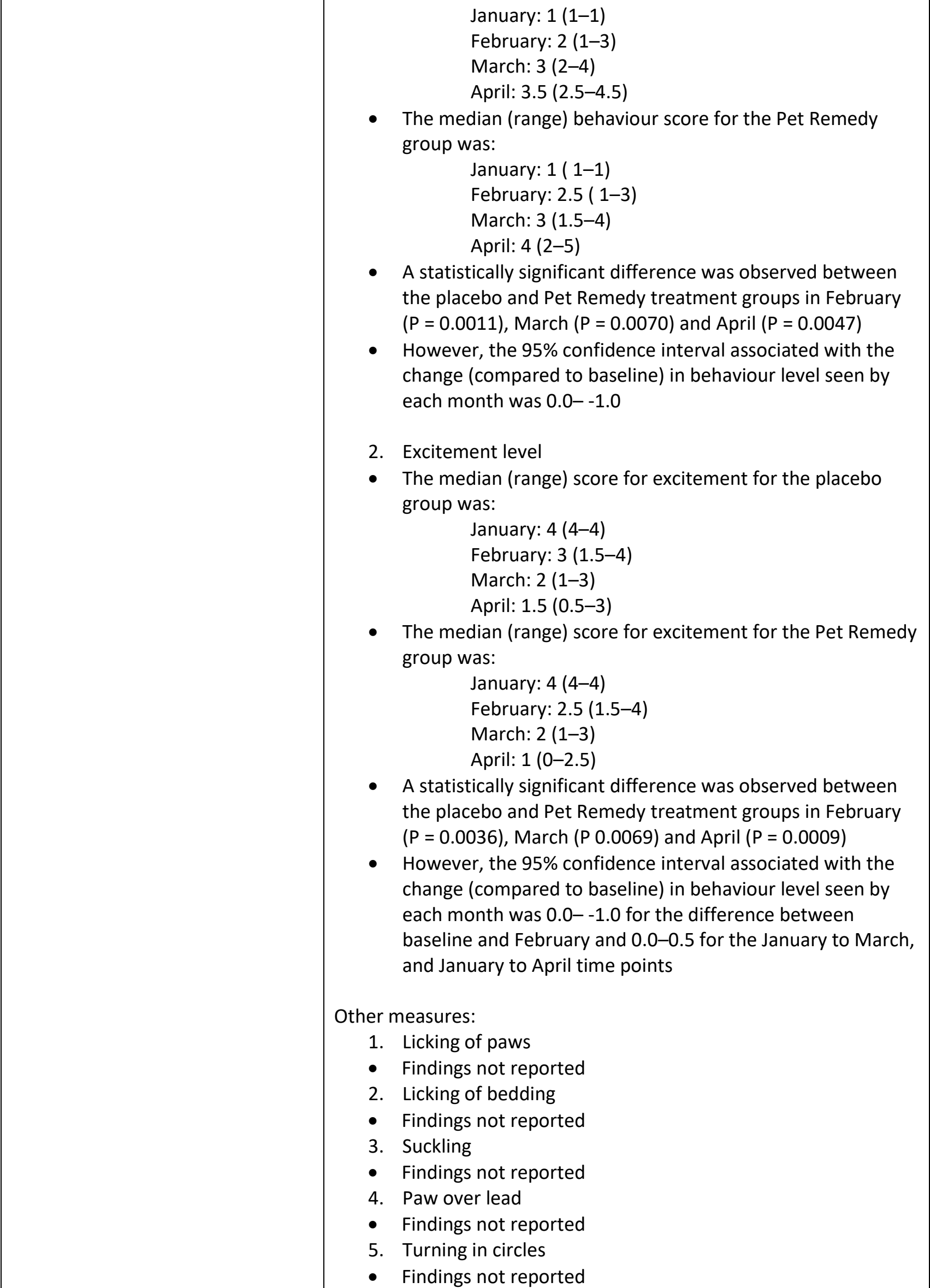 \\
\hline
\end{tabular}




\begin{tabular}{|c|c|}
\hline Limitations: & 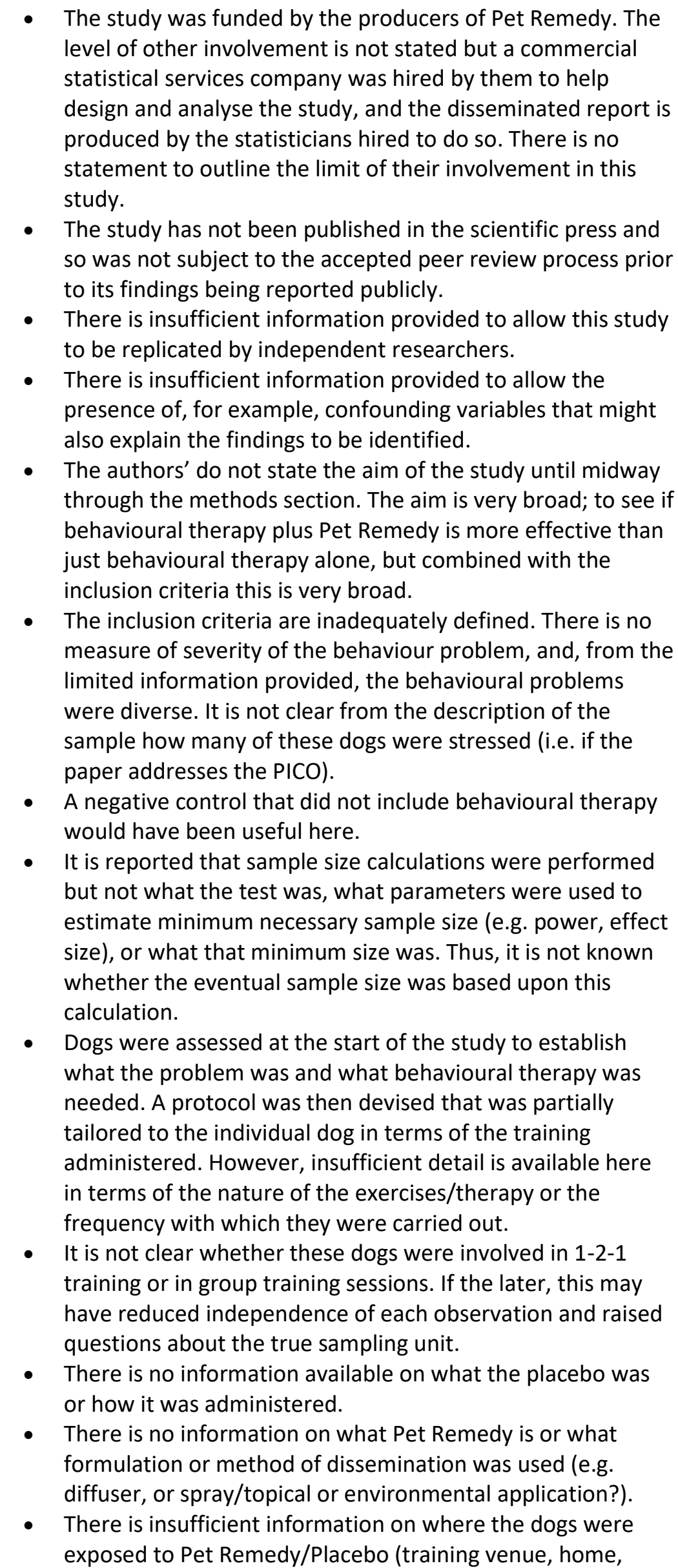 \\
\hline
\end{tabular}




\begin{tabular}{|c|c|}
\hline & 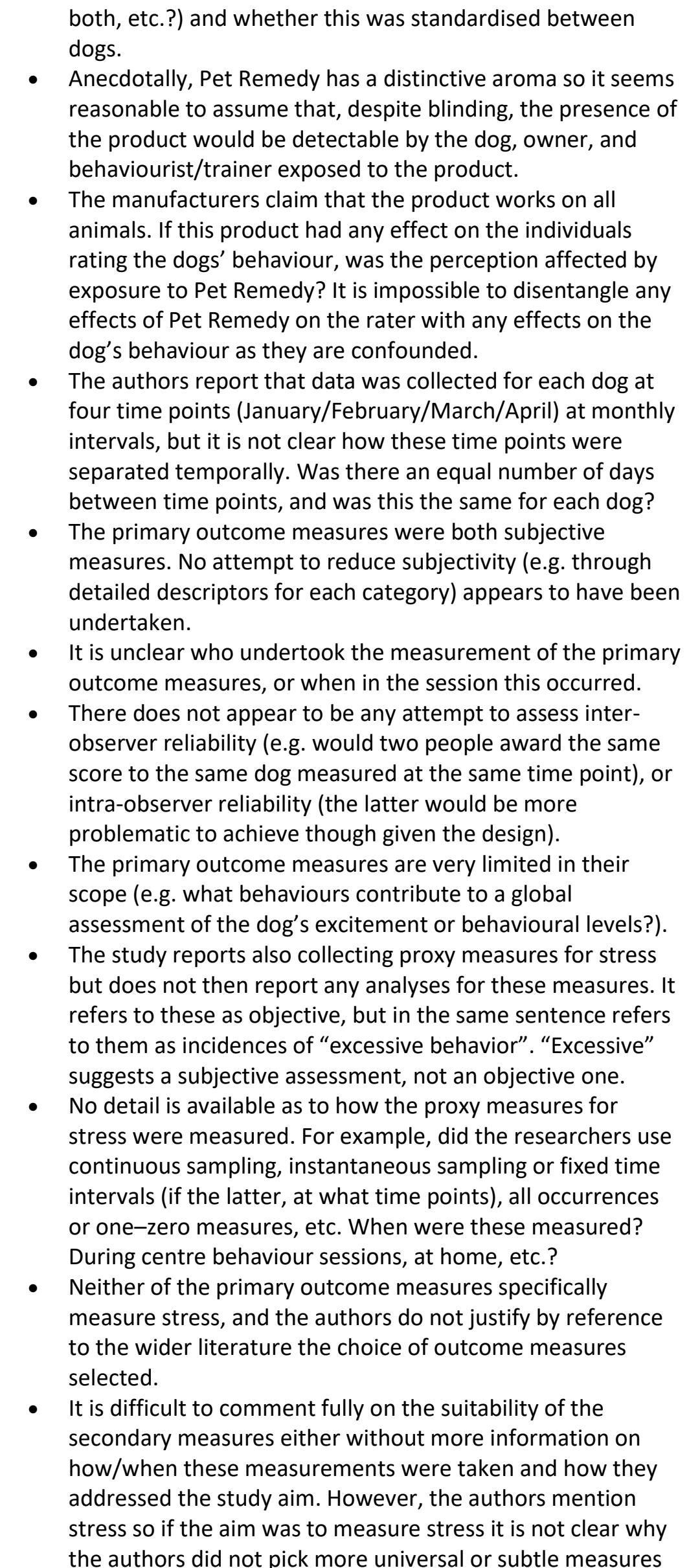 \\
\hline
\end{tabular}




\begin{tabular}{|l|l|}
\hline of potential stress like yawning. \\
It is not stated whether this study was reviewed by an ethics \\
committee or whether informed consent was obtained from \\
the clients. \\
The researchers do not report whether the data was \\
normally distributed or not, and present both parametric \\
and non-parametric measures for the raw data. The inter- \\
quartile range is not reported. The median is reported in this \\
Knowledge Summary as this reflects the type of analytical \\
statistics (non-parametric) that the authors undertook. \\
The lower boundary for the 95\% confidence interval for all \\
differences data parameters reported was 0.0, which could \\
mean that the true median value for the difference between \\
the two groups was zero (or no difference). Nb. It is \\
assumed median due to the values reported and the \\
distribution around the median difference value, but the \\
authors do not state this, and mean and standard deviation \\
values are also reported. The researchers do not \\
acknowledge this possibility in the summary of findings.
\end{tabular}

\section{Appraisal, application and reflection}

Three studies were included in this Knowledge Summary. Of the two directly using Pet Remedy, one found no efficacy of Pet Remedy in a stressed dog sample (Taylor and Madden, 2016) and the other found that it was efficacious at improving behaviour/reducing excitability in a sample of dogs that might be stressed (Unex Designs Ltd. 2014). The final study found a significant positive effect of Valerian alone (not as part of the Pet Remedy product) that might reflect lowered stress levels (Binks et al., 2018). All three studies focused on behavioural parameters as proxy measures of stress, and there are currently no studies that examine the effects of Pet Remedy (or its constituent parts applied environmentally/topically) on physiological signs of stress. This is a significant limitation to the current body of evidence examining the efficacy of Pet Remedy on canine stress.

The only study (Unex Designs Ltd., 2014) to show that Pet Remedy, as a product, had a positive effect on indices of canine behaviour was an industry designed, reported, and funded randomised controlled trial, and obtained direct from the producer of Pet Remedy, rather than via a peer reviewed journal. Industry sponsored pharmaceutical studies have been shown to be more likely to identify a significant positive effect when using their product in the human healthcare industry (e.g. Chartres et al., 2016; Lexchin et al., 2003). Studies associated with a financial tie are 3.23-4.05 times more likely to report a positive significant effect of the sponsor's product (Ahn et al., 2017; Lexchin et al., 2003). Whilst understudied in the veterinary profession, a similar effect has been observed with commercially funded studies significantly more associated with a positive outcome (Wareham et al., 2017). The peer review process, whilst recognised as imperfect (e.g. Smith, 2006), is an integral part of the scientific process, that is designed to improve the quality of scientific reporting. However, the producer claimed to have undertaken a scientific study, and historically had used this scientific output in literature supplied to veterinary professionals to support the use of Pet Remedy. Thus it was deemed appropriate to evaluate any relevant study for quality too as it was a resource that might be used to scientifically inform clinical decision making. Unfortunately, the level of detail provided in the submission does not permit an adequate evaluation of the quality of the scientific study, which limits evaluation of both internal and external validity. However, the reporting of the study was very low quality, with numerous omissions of information (see limitations section for the evaluation of this individual study) integral to understanding the scientific methodology utilised. Finally, if Pet Remedy is potentially efficacious for all mammals (Pet Remedy, 2018) then the assessor (as a fellow mammalian species) may also show altered behaviour when exposed to the product. They are also exposed to Pet Remedy at the same time as the dog and while making the 
assessment of the dog's behaviour. Therefore, there is a confounding variable here that means that, if there is an effect, it is impossible to disentangle it from an effect on the dog, the human (e.g. that influences their interpretation of the dog's behaviour) or various hypothetical interactions. Thus, it concluded that the study provided by Unex Designs Ltd. is unreliable and should not be used to inform the decision making of veterinary professionals. It underpins the importance of not simply relying on where the study type would sit on the pyramid of evidence when assessing experimental evidence.

By contrast, the study by Taylor and Madden (2016), whilst funded by Unex Designs Ltd. (2016) was otherwise independent of the funder. This study was also a randomised controlled trial that utilised a cross over design to assess the effects of an acute stressor (a novel environment combined with, it is assumed, solitary confinement) for a 30 minute duration. This study was the strongest in terms of addressing the PICO. Both the population studied and some of the outcomes measures to evaluate the effect of Pet Remedy most closely matched the requirement for dogs to be stressed and for the reduction in stress to be measured using parameters recognisable as at least partially associated with a stressed (or anxious/fearful) dog. Furthermore, the experimental methodology (video recording for later remote analysis by a blinded observer) removed an important source of bias and confound present in the Unex Designs Ltd. (2014) study. This study found no significant effects of Pet Remedy on 23 indices of canine behaviour. It is suggested that this study is a more reliable source of evidence for veterinary professionals to consult when considering using Pet Remedy in situations that may cause a susceptible dog to experience an increase in stress levels.

Finally, the Binks et al., 2018 quasi-experimental, fixed treatment order, controlled study was tentatively included, as Valerian is one of the primary herbs included in the Pet Remedy diffuser/spray and both products can be applied environmentally. Valerian was applied environmentally (on a scent cloth) in the Binks et al., (2018) study. Whilst the inclusion criteria was not specifically stress-associated (e.g. history of vet or owner identified susceptibility to stress, anxiety or fear) the rescue kennel environment is considered to be a significant stressor for rescue dogs (e.g. Hermiston et al., 2018) so it is reasonable to assume that dogs would be experiencing some stress. It should be noted though that the study excluded dogs considered most likely to be stressed in kennels. A key weakness here in relation to the PICO though, is that a baseline measurement to identify dogs that showed signs of stress was not undertaken. Whilst the control conditions preceded and concluded the order in which treatments were applied, these controls differed in terms of what they controlled for. The first control condition controlled for scent only (by providing a cloth that was also a novel inclusion within the dog's environment) so not a true baseline measurement. Furthermore, the outcome measures (a limited ethogram) used to evaluate the effects of Valerian on canine behaviour do not allow the reader to disentangle positive (e.g. excitement) and negative (e.g. stress) arousal states. However, it is worth noting that they did find a significant effect of Valerian on dog behaviour, with dogs showing reduced vocalisation and movement, and increased resting behaviour on days ( 3 consecutive days) when Valerian impregnated cloths were placed in the run. These findings might support the findings of the Unex Design Ltd. (2014) study and provide an alternative explanation (other than stress reduction) for any effect of Valerian based products on canine behaviour. However, using these findings to justify a specific product's use is more problematic given differences in the method of delivery, the concentration of the product, and the presence of synergistic, additive or negative/antagonistic effects that may be present in a product that combines multiple ingredients that may have a clinical effect on canine behaviour. Thus, while the findings of Binks et al., (2018) are interesting in relation to the potential use of Valerian to modify canine behavior, the external validity of this is not strong enough to use as evidence of efficacy of Pet Remedy, and more research is needed that uses Pet Remedy the product.

In conclusion, there is currently insufficient evidence to show that Pet Remedy does work as an environmental tool to reduce stress in dogs. The poorest quality evidence using a non-peer reviewed randomised controlled trial found a significant positive effect, but the findings are unreliable due to the quality of experimental design and inadequate reporting of the methodology and results. The strongest quality evidence, using a single blinded, randomised, controlled trial, found no effect of Pet Remedy on indices of canine behaviour. There is some evidence that Valerian (an active ingredient in Pet Remedy) may affect canine behaviour in a potentially stressful environment in the medium term, though the affective state sitting behind the behavioural change is unclear.

Given the anecdotal popularity of this product as an over-the-counter product to sell to pet owners, there is a 
need for further research to investigate the effect of Pet Remedy on both behavioural and physiological indices of canine stress levels across a range of common scenarios of relevance to the pet owner and veterinary professional. However, there is also no evidence that Pet Remedy will negatively affect canine stress levels either, with these findings consistent across all studies reviewed so, when used as an adjunct, it is unlikely to do any direct animal welfare harm. However, until further research demonstrates a positive effect of Pet Remedy, veterinary professionals should be cautious about recommending Pet Remedy as an alternative to options with a stronger evidentiary basis, or as a delay to seeking more extensive professional support where needed.

\section{Methodology Section}

\begin{tabular}{|c|c|}
\hline \multicolumn{2}{|l|}{ Search Strategy } \\
\hline $\begin{array}{r}\text { Databases searched and dates } \\
\text { covered: }\end{array}$ & $\begin{array}{l}\text { PubMed on NCBI platform } 1970 \text { - 12/06/2019; Web of Science: } 1970 \\
\text {-12/06/2019; CAB Abstracts on OVID platform: } 1973 \text { - week } 22 \\
2019 \\
\text { Grey literature search: } \\
\text { Request sent to the Pet Remedy supplier for copies of any studies } \\
\text { showing that Pet Remedy was efficacious (no species defined). } \\
\text { Original request (reply): } 31 / 05 / 2018 \text { (31/05/2018), request for } \\
\text { updates: } 25 / 10 / 2018, \text { no reply received by the time of submission of } \\
\text { this Knowledge Summary for review (01/11/2018), or by the time } \\
\text { the revised draft was submitted ( } 21 / 02 / 2019) \text {, or by the time the } \\
\text { final draft proof was approved by the author for publication } \\
\text { (12/06/2019). }\end{array}$ \\
\hline Search terms: & $\begin{array}{l}\text { PubMed: } \\
\text { (Dog or dogs or canine or canines or canis or canid or pup or puppy } \\
\text { or puppies or bitch or bitches) AND ("Pet Remedy" or Valerian or } \\
\text { vetiver or "sweet basil" or "clary sage" or herb or herbs or herbal or } \\
\text { "chrysopogon zizanioides" or "ocimum basilicum" or "salvia sclaria" } \\
\text { or "Valeriana officinalis") AND (Stress or stressed or stressor or } \\
\text { stressful or fear or fearful or anxious or anxiety or phobia or phobic } \\
\text { or distress or worried or nervous or panic or fright or scared or } \\
\text { alarm or apprehensive or calm or calming or calmed) } \\
\text { Web of Science: } \\
\text { (Dog or dogs or canine or canines or canis or canid or pup or puppy } \\
\text { or puppies or bitch or bitches) AND ("Pet Remedy" or Valerian or } \\
\text { vetiver or "sweet basil" or "clary sage" or herb or herbs or herbal or } \\
\text { "chrysopogon zizanioides" or "ocimum basilicum" or "salvia sclaria" } \\
\text { or "Valeriana officinalis") AND (Stress or stressed or stressor or } \\
\text { stressful or fear or fearful or anxious or anxiety or phobia or phobic } \\
\text { or distress or worried or nervous or panic or fright or scared or } \\
\text { alarm or apprehensive or calm or calming or calmed) } \\
\text { CAB Abstracts: } \\
\text { (Dog or dogs or canine or canines or canis or canid or pup or puppy } \\
\text { or puppies or bitch or bitches) AND (Pet Remedy or Valerian or } \\
\text { vetiver or sweet basil or clary sage or herb or herbs or herbal or }\end{array}$ \\
\hline
\end{tabular}




\begin{tabular}{|l|l|}
\hline & $\begin{array}{l}\text { chrysopogon zizanioides or ocimum basilicum or salvia sclaria or } \\
\text { Valeriana officinalis) AND (Stress or stressed or stressor or stressful } \\
\text { or fear or fearful or anxious or anxiety or phobia or phobic or } \\
\text { distress or worried or nervous or panic or fright or scared or alarm } \\
\text { or apprehensive or calm or calming or calmed) }\end{array}$ \\
\hline Dates searches performed: & $\begin{array}{l}\text { PubMed: } 12 / 06 / 2019 ; \text { Web of Science: } 12 / 06 / 2019 ; \text { CAB Abstracts: } \\
12 / 06 / 2019\end{array}$ \\
\hline
\end{tabular}

\section{Exclusion / Inclusion Criteria}

Exclusion: Pre-defined exclusion criteria: non-English language, popular press articles, conference abstracts

Inclusion: Any comparative (control group utilised) study in which the effect of Pet Remedy (or its constituent parts, applied environmentally or topically) on stress (or similar) in dogs was studied.

\begin{tabular}{|c|c|c|c|c|c|c|}
\hline \multicolumn{7}{|c|}{ Search Outcome } \\
\hline Database & $\begin{array}{c}\text { Number } \\
\text { of } \\
\text { results }\end{array}$ & $\begin{array}{c}\text { Excluded - } \\
\text { did not } \\
\text { answer } \\
\text { PICO } \\
\text { question }\end{array}$ & $\begin{array}{c}\text { Excluded - not } \\
\text { English } \\
\text { language }\end{array}$ & $\begin{array}{l}\text { Excluded - } \\
\text { conference } \\
\text { abstract only }\end{array}$ & $\begin{array}{l}\text { Excluded - } \\
\text { duplicates }\end{array}$ & $\begin{array}{c}\text { Total } \\
\text { relevant } \\
\text { papers }\end{array}$ \\
\hline Pubmed & 41 & 40 & 0 & 0 & 0 & 1 \\
\hline $\begin{array}{l}\text { Web of } \\
\text { Science }\end{array}$ & 46 & 44 & 0 & 0 & 1 & 1 \\
\hline $\begin{array}{l}\text { CAB } \\
\text { Abstracts }\end{array}$ & 88 & 86 & 0 & 0 & 0 & 1 \\
\hline $\begin{array}{l}\text { Pet Remedy } \\
\text { - direct } \\
\text { request for } \\
\text { information }\end{array}$ & 6 & 5 & 0 & 0 & 0 & 1 \\
\hline \multicolumn{6}{|c|}{ Total relevant papers when duplicates removed } & 3 \\
\hline
\end{tabular}

\section{CONFLICT OF INTEREST}

The author declares no conflicts of interest. 


\section{REFERENCES}

1. Ahn, R., Woodbridge, A., Abraham, A., Saba, S., Korenstein, D., Madden, E., Boscardin, W. J. and Keyhani, S. 2017. Financial ties of principal investigators and randomized controlled trial outcomes: cross sectional study. British Medical Journal 356:i6770. DOI: https://doi.org/10.1136/bmj.i6770

2. Binks, J., Taylor, S., Wills, A. and Montrose, T. 2018. The behavioural effects of olfactory stimulation on dogs at a rescue centre. Applied Animal Behaviour Science 202: 69-76.

DOI: https://doi.org/10.1016/j.applanim.2018.01.009

3. Chartres, N., Fabbri, A. and Bero, L. A. 2016. Association of industry sponsorship with outcomes of nutrition studies: a systematic review and meta-analysis. JAMA Internal Medicine 176(12): 1769-1777.

DOI: https://doi.org/10.1001/jamainternmed.2016.6721

4. Hermiston, C., Montrose, V. T., and Taylor, S. 2018. The effects of dog-appeasing pheromone spray upon canine vocalizations and stress-related behaviors in a rescue shelter. Journal of Veterinary Behavior: Clinical Applications and Research (26): 11-16.

DOI: https://doi.org/10.1016/j.jveb.2018.03.013

5. Kelly, J., Sadeghieh, T. and Adeli, K. 2014. Peer Review in Scientific Publications: Benefits, Critiques, \& A Survival Guide. The Journal of the International Federation of Clinical Chemistry and Laboratory Medicine 25(3): 227-243.

6. Lexchin, J., Bero, L. A., Djulbegovic, B. and Clarke, O. 2003. Pharmaceutical industry sponsorship and research outcome and quality: systematic review. British Medical Journal 326:1167.

DOI: https://doi.org/10.1136/bmj.326.7400.1167

7. Pet Remedy. 2018. Pet Remedy: natural de-stress and calming. [online] Unex Designs Ltd. (Accessed: 01/11/2018).

8. Smith, R. 2006. Peer review: a flawed process at the heart of science and journals. Journal of the Royal Society of Medicine 99: 178-182. DOI: https://doi.org/10.1177/014107680609900414

9. Taylor, S. and Madden, J. 2016. The effect of Pet Remedy on the behavior of the domestic dog (Canis familiaris). Animals 6(11), 64. DOI: https://doi.org/10.3390/ani6110064

10. Unex Designs Ltd. (2014) Statistical analysis of a new Animal Behaviour Centre dog trial for Pet Remedy: final analysis - three-month follow-up. Select Statistical Services, Exeter, Devon. Document supplied by Unex Designs Ltd. by email on 31/05/2018.

11. Wareham, K. J., Hyde, R. M., Grindlay, D., Brennan, M. L. and Dean, R. S. 2017. Sponsorship bias and quality of randomised controlled trials in veterinary medicine. BMC Veterinary Research 13: 234. DOI: https://doi.org/10.1186/s12917-017-1146-9 


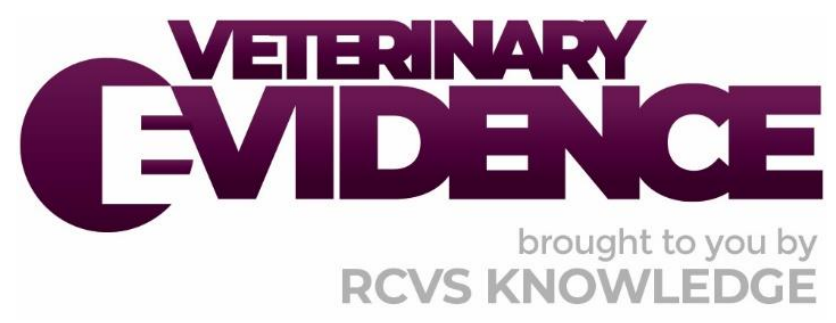

\section{Intellectual Property Rights}

Authors of Knowledge Summaries submitted to RCVS Knowledge for publication will retain copyright in their work, and will be required to grant RCVS Knowledge a non-exclusive license of the rights of copyright in the materials including but not limited to the right to publish, re-

publish, transmit, sell, distribute and otherwise use the materials in all languages and all media throughout the world, and to license or permit others to do so.

\section{Disclaimer}

Knowledge Summaries are a peer-reviewed article type which aims to answer a clinical question based on the best available current evidence. It does not override the responsibility

of the practitioner. Informed decisions should be made by considering such factors as individual clinical expertise and judgement along with patient's circumstances and owners' values. Knowledge Summaries are a resource to help inform and any opinions expressed within the Knowledge Summaries are the author's own and do not necessarily reflect the view of the RCVS Knowledge. Authors are responsible for the accuracy of the content. While the

Editor and Publisher believe that all content herein are in accord with current recommendations and practice at the time of publication, they accept no legal responsibility

for any errors or omissions, and make no warranty, express or implied, with respect to material contained within.

For further information please refer to our Terms of Use.

RCVS Knowledge is the independent charity associated with the Royal College of Veterinary Surgeons (RCVS). Our ambition is to become a global intermediary for evidence based veterinary knowledge by providing access to information that is of immediate value to practicing veterinary professionals and directly contributes to evidence based clinical decision-making.

https://www.veterinaryevidence.org/

RCVS Knowledge is a registered Charity No. 230886.

Registered as a Company limited by guarantee in England and Wales No. 598443.

Registered Office: Belgravia House, 62-64 Horseferry Road, London SW1P 2AF



This work is licensed under a Creative Commons Attribution 4.0 International License

\section{Veterinary Evidence}

